\title{
Assertive outreach: mirror-image study with contemporaneous controls
}

\author{
Ann M. Mortimer, ${ }^{1}$ Charles J. Shepherd, ${ }^{1}$ Akin Fadahunsi, ${ }^{2}$ Adam Jones, ${ }^{3}$ \\ Palanivelu Kumar, ${ }^{4}$ Poornima Gangaram ${ }^{5}$
}

The Psychiatrist (2012), 36, 245-248, doi: 10.1192/pb.bp.111.036970

${ }^{1}$ University of Hull; ${ }^{2}$ Humber Foundation NHS Trust; ${ }^{3}$ Hull York Medical School; ${ }^{4}$ Lancashirecare Foundation NHS Trust; ${ }^{5}$ Penninecare NHS Foundation Trust

Correspondence to Ann M. Mortimer (a.m.mortimer@hull.ac.uk)

First received 22 Sep 2011, final revision 1 Dec 2011, accepted 9 Jan 2012

\begin{abstract}
Aims and method To evaluate the suitability of 80 patients referred for assertive outreach treatment (AOT) and their treatment outcomes, by comparing clinical and social data during the treatment period with data before treatment began. To control for service development across the board, patients on ordinary community treatment were identified and matched to patients undergoing AOT for age, gender, clinical diagnosis and duration, and data acquired for the same time period as the patients on AOT. This was a retrospective mirror-image evaluation with contemporaneous controls.
\end{abstract}

\begin{abstract}
Results The patients referred for AOT were more socially disadvantaged and had used more clinical resources than the control patients. Overall, AOT reduced resource uptake markedly following referral, while resource uptake by control patients during the same period remained static or increased; AOT, however, did not lessen most aspects of social disadvantage.
\end{abstract}

Clinical implications The advantages of AOT include much reduced use of services but not the resolving of social exclusion. Some ordinary community provision may fail to afford the quality of AOT and thus suffer by comparison. The demise of AOT may be premature in such services.

Declaration of interest None.
Up to 1 in 500 people with severe mental illness are difficult to engage. ${ }^{1}$ Consequences for patients include social exclusion, offending, homelessness, substance misuse, poor physical health, frequent unplanned psychiatric admission (often compulsory), overdose, risk to other people, poor social function, stigma and isolation. Such patients consume disproportionate National Health Service (NHS) and related resources and overall are treated ineffectively. The 2001 NHS Plan envisaged 220 assertive community treatment services, generally known as assertive outreach treatment (AOT) in the UK, treating 20000 such patients by 2003; these targets were largely met. Characteristic features of AOT include long-term retention of patients, delivery of services outside standard settings, intensive interventions, inclusion of carers, multidisciplinary and multi-agency staffing, and assistance with non-clinical issues such as housing, employment and finances. There is a particular focus on engagement, team working and extended hours. The aim of AOT is to improve mental health and ameliorate risk to others by increasing the effectiveness of treatment and reducing social exclusion.

Several influential studies, however, have cast doubt on the effectiveness of AOT compared with ordinary community mental health treatment. A national observation study attributed reductions in admissions and bed days to the inception of crisis and home treatment teams rather than $\mathrm{AOT}^{2}$ A systematic review and meta-regression suggested that AOT reduced bed use only when it was high already. ${ }^{3}$ Subsequently, a randomised controlled trial of 250 patients over 3 years determined that AOT provided no greater clinical benefit than ordinary community treatment, at the same or greater cost than ordinary treatment., ${ }^{4,5}$ Consequently, AOT services are at risk of dissolution: a third of AOT services in a recent nationwide survey were undergoing review, being reconfigured or closed. ${ }^{6}$ Even so, uncontrolled studies continue to demonstrate the effectiveness of AOT, such as in reducing bed use ${ }^{7}$ and reducing admission rates. ${ }^{8}$

The retrospective controlled study presented here included a large complete sample of patients undergoing AOT within the Humber Trust in Hull between 2002 and 2009. Data from contemporaneous control patients of the trust's community mental health team (CMHT) services were used to nullify the effects of service reconfigurations affecting all patients during the period under study. It is proposed that this naturalistic sample affords a different perspective on the results of AOT in real practice. 


\section{Method}

This was a retrospective mirror-image case-note evaluation of all patients transferred to AOT in Hull from service inception in 2002. Before service inception, locality based community teams had identified which patients were deemed suitable for transfer to AOT; this initial cohort gradually entered the new service and further patients were referred over the ensuing years.

Clinical and social data on all the patients were gathered at three time points: the date of transfer to the AOT service, the current date (i.e. when the data were collected from case notes - ascertainment), and the date of an equivalent time period before the patient was transferred; for instance, if the patient was transferred in April 2004, and the notes were being looked at for the study in April 2008, data were gathered about the patient's status in April 2000, April 2004 and April 2008. Between the period before treatment and the period during treatment, data were collected regarding consequential clinical events; this was expressed as the number of events per year.

Control patients were ascertained from the CMHT case-loads in Hull. The controls were individually matched to patients in the AOT group using clinical diagnosis, gender, duration of mental disorder since first presentation to psychiatric services (within 5 years) and age (within 5 years). The control patients' case notes were studied at the same three time points, and thus between the same periods, as the patients on AOT to whom they had been matched, and the same types of data were collected.

Data recorded at the three time points for each patient (retrospective, transfer and ascertainment dates) included accommodation status, occupation status, relationship status, alcohol misuse, drug misuse and current medication. Event rate data, expressed per year, included loss of housing, gaining or losing employment or training, separations, new relationships, forensic events, number of admissions, weeks spent as an in-patient, weeks under crisis or home intensive treatment, number of Mental Health Act detentions, weeks spent detained and instances of overdose.

Data from patients on AOT and control patients were analysed using SPSS version 13 for Windows. The groups were compared at baseline using the $\chi^{2}$-test, $t$-test or Mann-Whitney $U$-test as appropriate. Cross-sectional data were compared between the two groups at each of the three time points using cross-tabulation and the $\chi^{2}$ statistic. Event rate data were compared between the groups before and after the transfer date, using the univariate general linear model, with baseline event rates as a cofactor.

\section{Results}

A total of 80 patients on AOT were ascertained; control patients were matched for 73 of these. There were particular difficulties in matching the duration of the disorder, which tended to be excessive in patients on AOT. Statistical scrutiny of the seven patients on AOT with no matched controls demonstrated they did not differ from the rest of the group in any respect, including duration, which was shorter (mean 16 years, s.d. $=8$ years); therefore, these patients were included in the analysis.

Complete sets of notes were acquired for all patients. The notes were extensive and no missing values were recorded for any of the variables. Key workers were approached regarding any discrepancies or unclear information.

Of the patients, $71 \%$ were male and $29 \%$ female; $97 \%$ were White British. We noted that Hull, although a port city, has an unusually small population of minority ethnic people. The principal clinical diagnosis was schizophrenia in $80 \%$ of the patients, and bipolar disorder in the remainder. The mean age of the patients was 43 years (s.d. $=10$, range 26-67). The mean duration of the disorder since first presentation was 18 years (s.d. $=9$, range $4-42$ ). There were no significant differences between the patients on AOT and the control patients regarding diagnosis, age, gender or duration of the disorder. The mean time within the AOT service was 52 months (s.d. $=24$, range 11-100). The total time evaluated across both groups before and after the AOT period was 1326 patient-years.

\section{Cross-sectional issues}

Results are shown in Table 1.

Patients on AOT were less likely than the control patients to be living with their parents or in specialist mental health housing across all three time points (retrospective $\chi^{2}=10.84, P=0.03$; transfer $\chi^{2}=9.67, P=0.05$; ascertainment $\left.\chi^{2}=11.90, P=0.02\right)$. Patients on AOT were more likely than control patients to be homeless or living alone, particularly at the time of transfer to AOT, although these differences were not significant. Over twice as many of the patients on AOT had moved to supported housing by the time of ascertainment, compared with the transfer date before AOT.

There were no differences in occupation status, except that $98 \%$ of the patients on AOT had no occupation, education, training or voluntary work at ascertainment, compared with $81 \%$ of the control patients. This was statistically significant $\left(\chi^{2}=10.80, P<0.01\right)$.

The vast majority of patients on AOT and control patients were not in a relationship, with very low rates $(<5 \%)$ of cohabitation at any time point. Patients on AOT were more likely than control patients to be single at all time points (retrospective $\chi^{2}=8.67, P=0.01$; transfer $\chi^{2}=6.8, P=0.03$; ascertainment $\chi^{2}=5.80, P=0.05$ ).

Rates of drug and alcohol misuse and dependence declined in both groups over time, but patients on AOT were significantly more likely to be misusing or dependent on alcohol at the time of transfer $\left(\chi^{2}=8.30, P=0.03\right)$.

There was an increase in the use of depot medication and clozapine in both groups over time.

\section{Event rate data}

Results are shown in Table 1.

Comparing the period of AOT treatment with the period before it, there were no differences between the patients on AOT and the control patients regarding events such as loss or gain of housing, relationship or occupation. There were no differences in the rates of 


\begin{tabular}{|c|c|c|c|c|}
\hline Variable & Time point/period & AOT/control & Value & $P$ \\
\hline Living with parents/in specialist mental health housing, \% & $\begin{array}{l}\text { Retrospective } \\
\text { Transfer } \\
\text { Ascertainment }\end{array}$ & $\begin{array}{l}\text { AOT } \\
\text { Control } \\
\text { AOT } \\
\text { Control } \\
\text { AOT } \\
\text { Control }\end{array}$ & $\begin{array}{l}19 \\
40 \\
27 \\
45 \\
26 \\
45\end{array}$ & $\begin{array}{l}0.03 \\
0.05 \\
0.02\end{array}$ \\
\hline Lack of occupation, training, education, voluntary work, \% & Ascertainment & $\begin{array}{l}\text { AOT } \\
\text { Control }\end{array}$ & $\begin{array}{l}98 \\
81\end{array}$ & 0.01 \\
\hline Single status, \% & $\begin{array}{l}\text { Retrospective } \\
\text { Transfer } \\
\text { Ascertainment }\end{array}$ & $\begin{array}{l}\text { AOT } \\
\text { Control } \\
\text { AOT } \\
\text { Control } \\
\text { AOT } \\
\text { Control }\end{array}$ & $\begin{array}{l}84 \\
62 \\
92 \\
76 \\
88 \\
72 \\
\end{array}$ & $\begin{array}{l}0.01 \\
0.03 \\
0.05\end{array}$ \\
\hline Alcohol misuse or dependence, \% & Transfer & $\begin{array}{l}\text { AOT } \\
\text { Control }\end{array}$ & $\begin{array}{l}38 \\
19 \\
\end{array}$ & 0.03 \\
\hline Weeks per patient per year detained under Mental Health Act 1983 & $\begin{array}{l}\text { Before AOT } \\
\text { During AOT }\end{array}$ & $\begin{array}{l}\text { AOT } \\
\text { Control } \\
\text { AOT } \\
\text { Control }\end{array}$ & $\begin{array}{l}7.5 \\
1.0 \\
5.0 \\
1.4 \\
\end{array}$ & 0.01 \\
\hline Total admissions per patient per year & $\begin{array}{l}\text { Before AOT } \\
\text { During AOT }\end{array}$ & $\begin{array}{l}\text { AOT } \\
\text { Control } \\
\text { AOT } \\
\text { Control }\end{array}$ & $\begin{array}{l}0.88 \\
0.31 \\
0.55 \\
0.29\end{array}$ & 0.03 \\
\hline Total weeks admitted per patient per year & $\begin{array}{l}\text { Before AOT } \\
\text { During AOT }\end{array}$ & $\begin{array}{l}\text { AOT } \\
\text { Control } \\
\text { AOT } \\
\text { Control }\end{array}$ & $\begin{array}{l}11.0 \\
2.3 \\
6.5 \\
3.5 \\
\end{array}$ & 0.03 \\
\hline Weeks per patient per year under crisis service & $\begin{array}{l}\text { Before AOT } \\
\text { During AOT }\end{array}$ & $\begin{array}{l}\text { AOT } \\
\text { Control } \\
\text { AOT } \\
\text { Control }\end{array}$ & $\begin{array}{l}0.76 \\
0.35 \\
0.04 \\
0.24 \\
\end{array}$ & 0.01 \\
\hline Overdoses per patient per year & $\begin{array}{l}\text { Before AOT } \\
\text { During AOT }\end{array}$ & $\begin{array}{l}\text { AOT } \\
\text { Control } \\
\text { AOT } \\
\text { Control }\end{array}$ & $\begin{array}{l}0.03 \\
0.03 \\
0.00 \\
0.05\end{array}$ & 0.04 \\
\hline
\end{tabular}

AOT, assertive outreach treatment.

offending, the number of weeks spent in prison or the number of Mental Health Act detentions. The number of weeks detained per year reduced in patients on AOT but rose in the control patients; this was statistically significant according to the univariate general linear model $(F=5.76, P=0.01)$. Similarly, the patients on AOT enjoyed a statistically superior reduction in number of admissions over time $(F=5.67, P=0.04)$ : the number of weeks per year spent as an in-patient fell in the patients on AOT and went up in the control patients $(F=3.84$, $P=0.03)$.

The mean number of weeks per year spent with the crisis service during treatment decreased in both the patients on AOT and the control patients, but the outcome in the patients on AOT was statistically superior $(F=5.02$, $P=0.01)$. Episodes of overdose were rare in both groups. No patients on AOT took an overdose during the treatment period, while there was a small rise in overdose in the control patients; this was statistically significant $(F=3.4$, $P=0.02)$.

\section{Discussion}

Retrospective case-note studies are criticised for using a data source that may be incomplete. This was not our impression of this study, however; for all patients ascertained, there was a plethora of paperwork, especially in respect to admissions. This does not exclude, however, that the notes may have missed some of the more peripheral data, such as offences.

This naturalistic retrospective study demonstrates that patients transferred to the AOT service were appropriate to the service, compared with control patients with the same clinical diagnosis, gender, approximate age and approximate duration of psychosis, who were not referred. Patients on AOT were more disadvantaged than the control patients in terms of housing, occupation, relationships and substance misuse, and used more clinical resources. Despite this, AOT succeeded in reducing overdose and crisis service use more than control CMHT treatment; reduced total admission rates, this being almost static in the control patients; and 
reduced the number of weeks spent detained, which rose in the control patients. The number of weeks admitted per year dropped by $40 \%$ in the patients on AOT and increased in the control patients.

Whether AOT is worthy of preservation is a vexed matter. The results of this study vary markedly from those of the REACT study. ${ }^{4}$ This is hardly surprising, since the methodology and patients are completely different. Our patients were selected for AOT, and therefore entered this study according to clinical opinion and not because of a recent history of lengthy in-patient treatment. Indeed, $12 \%$ of our patients on AOT had not been admitted at all during the equivalent period before transfer to AOT, two-thirds had been admitted less than once per year during the period, and $52 \%$ had spent less than 50 days per year as in-patients during the period. None of these patients would have been eligible for the REACT study, and yet they were demonstrably more disadvantaged than the control patients not referred for AOT. Moreover, in contrast to the findings of Burns and colleagues, ${ }^{3}$ our patients, despite previously using fewer in-patient resources than those selected for the REACT study, succeeded in substantially reducing their bed occupancy under AOT, to an extent that was statistically superior to that achieved by control patients under CMHT care.

There are two related possible explanations for our findings and their discrepancy with the REACT study. One explanation, which we consider likely, is that Hull CMHT treatment was of relatively poor quality, so the AOT model easily delivered superior outcomes despite the disadvantaged nature of its patients. The AOT staff were drawn from existing CMHTs and social care at inception, and these members of staff may have been self-selected in terms of enthusiasm for and dedication to the new service. Staffing proved exceptionally stable, with only one member leaving for a promotion throughout. Medical staffing consisted of a consultant and associate specialist, who had chosen to cover this service. By contrast, the Hull CMHTs were characterised by long-term consultant vacancies and extensive case-loads throughout the period. ${ }^{9}$

This explanation contrasts with the argument that the reason for lack of divergence between AOT and treatment as usual in the REACT study was that treatment as usual has now developed sufficient quality to manage difficult patients without the expensive and superfluous tenets of the AOT model. On the other hand, it may be that the patients in the REACT study were overselected in terms of their severity, and that this overcame the extra treatment resources provided to the AOT group. In other words, the most difficult patients all do as badly, no matter what the treating team tries to do with them.

Whatever the truth behind our findings and their inconsistency with the REACT study, the question of whether AOT has overall been an effective use of resources remains unresolved. There is perhaps a need to investigate the longer-term outcomes of patients formerly managed by AOT services that have closed or otherwise lost their fidelity to the service model in the future.

\section{About the authors}

Ann M. Mortimer is foundation chair in psychiatry and Charles J. Shepherd is senior research nurse at the University of Hull. Akin Fadahunsi is locum consultant at the Humber Foundation NHS Trust. Adam Jones is a fourthyear medical student at Hull York Medical School. Palanivelu Kumar is consultant psychiatrist at the Lancashirecare Foundation NHS Trust. Poornima Gangaram is consultant psychiatrist at the Penninecare NHS Foundation Trust.

\section{References}

1 Sainsbury Centre for Mental Health. Keys to Engagement. Sainsbury Centre for Mental Health, 1998.

2 Glover G, Arts G, Babu KS. Crisis resolution/home treatment teams and psychiatric admission rates in England. Br J Psychiatry 2006; 189: 441-5.

3 Burns T, Catty J, Dash M, Roberts C, Lockwood A, Marshall M. Use of intensive case management to reduce time in hospital in people with severe mental illness: systematic review and meta-regression. BMJ 2007; 335: 336

4 McCrone $\mathrm{P}$, Killaspy $\mathrm{H}$, Bebbington $\mathrm{P}$, Johnson S, Nolan F, Pilling $\mathrm{S}$, et al. The REACT study: cost-effectiveness analysis of assertive community treatment in north London. Psychiatr Serv 2009; 60: 908-13.

5 Killaspy H, Kingett S, Bebbington P, Blizard R, Johnson S, Nolan F, et al Randomised evaluation of assertive community treatment: 3-year outcomes. Br J Psychiatry 2009; 195: 81-2.

6 Ghosh R, Killaspy H. A national survey of assertive community treatment services in England. J Ment Health 2010; 19: 500-8.

7 Hussain A, Thirkell T, Taher A. Enhancing the effectiveness of an assertive outreach team: case study. Psychiatrist 2011; 35: 266-8.

8 Rana T, Commander M. Long-term follow-up of individuals on assertive outreach teams. Psychiatrist 2010; 34: 88-91.

9 Dale C, Rosenberg M, Green P. Report of the Independent Investigation into the Care and Treatment of B. SUI ref. 2005/95. Caring Solutions UK, 2008 (http://www.yorksandhumber.nhs.uk/document.php?o=2578). 